E.J. W. van Veen

W. E. Monteban-Kooistra

J. H. J. M. Meertens

J. J. M. Ligtenberg

J. E. Tulleken

J. G. Zijlstra

\section{Recombinant human activated factor VII in postpartum hemorrhagic shock: the dark side}

Accepted: 10 July 2007

Published online: 1 August 2007

(C) Springer-Verlag 2007

Sir: A 38-year-old woman (gravida 2, para 3) was referred to our hospital because of intractable postpartum hemorrhagic shock. During this gemelli pregnancy she was admitted to the hospital three times for vaginal blood loss. Ultrasonography revealed a hematoma and a placenta close to the cervical ostium. Coagulation and platelets were normal. Because of fetal distress during spontaneous labor at 34 weeks an emergency cesarean section was performed. Vaginal hemorrhage began after abdominal closure. Management consisted of uterotonic drugs, intravenous fluids, red blood cells, and fresh frozen plasma without effect. Supravaginal hysterectomy was deemed necessary. Because of pelvic oozing the abdomen was closed after packing of the pelvis. She was still in hemorrhagic shock. Recombinant human activated factor VIIa (rFVIIa; NovoSeven) was administered twice as a 7.2-mg intravenous bolus at an interval of $120 \mathrm{~min}$, but bleeding continued from almost all orifices. The next day she was referred. Hemodynamic instability persisted, and multiorgan failure developed. Angiography of the pelvic arteries resulted in coiling of three small arteries, but hemostasis was not achieved. On the third day tranexamic acid was added and, after lack of effect, a 9-mg intravenous bolus of rFVIIa $(90 \mu \mathrm{g} / \mathrm{kg})$. Coagulation parameters improved and for several hours the hemoglobin level was stable, but she developed blistering of arms, fingers, and feet with slow

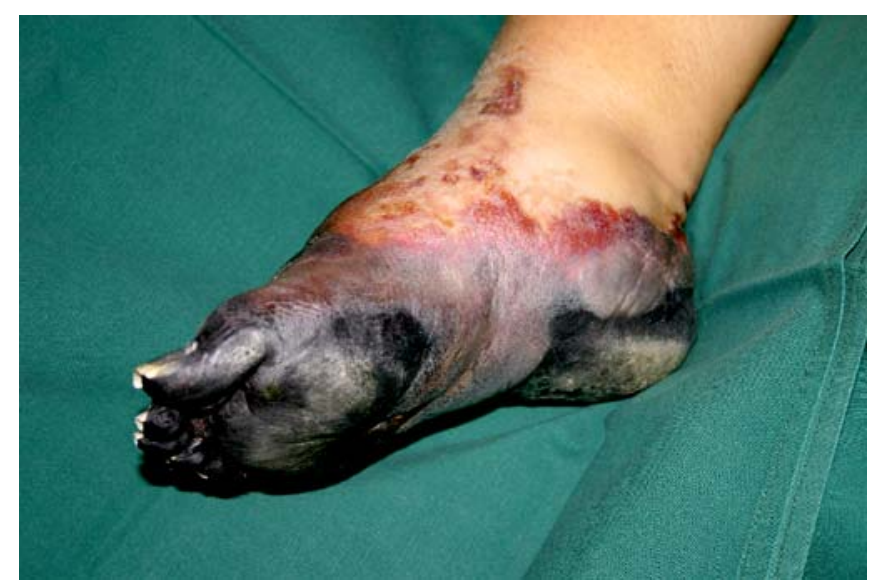

Fig. 1 Right foot of the patient

capillary refill. Toes, heel, and sole of the right foot became black and cold. On laparotomy packings and 91 blood and cloths were removed. Afterwards there was no bleeding. The ischemia worsened in a few days and spread to the fore foot (Fig. 1) resulting in amputation of the lower extremity. Necrosis also developed on the dorsal side of the left fore arm. Other acra were cyanotic but did not become necrotic. Since delivery she had received $48 \mathrm{U}$ red blood cells, $30 \mathrm{U}$ fresh frozen plasma and $17 \mathrm{U}$ five donors each of platelets. Multiorgan failure improved, and 19 days after admission the patient was discharged to the ward.

rFVIIa use has been reported for severe postpartum hemorrhage $[1,2]$. Immediately after administration of the third dose of rFVIIa hemostasis was indeed reached. However, severe thromboembolic complications occurred. Although there seems to be a relationship in time between the onset of complications and moment of drug administration, it is hard to confirm this relationship. rFVIIa overdosing or sepsis may also play a role. However, there was no positive confirmation of infection.

The incidence of thrombotic complications in licensed use is $1-2 \%$. Most thromboembolic events have followed off-label use of rFVIIa [3]. Off-label rFVIIa is used principally in desperate situations. However, to make a balanced choice, even then we need to have an impression of the complication rate. Safety and efficacy in off-label use must be studied [4]. Pregnant and postpartum women should receive special attention in these studies because of their particular coagulation condition. 


\section{References}

1. Franchini M, Lippi G, Franchi M (2007) The use of recombinant activated factor VII in obstetric and gynaecological haemorrhage. Br J Obstet Gynaecol 114:8-15

2. Haynes J, Laffan M, Plaat F (2007) Use of recombinant activated factor VII in massive obstetric haemorrhage. Int $\mathbf{J}$ Obstet Anesth 16:40-49
3. O'Connell KA, Wood JJ, Wise RP, Lozier JN, Braun MM (2006) Thromboembolic adverse events after use of recombinant human coagulation factor VIIa. JAMA 295:293-298

4. Levi M, Peters M, Buller HR (2005) Efficacy and safety of recombinant factor VIIa for treatment of severe bleeding: a systematic review. Crit Care Med 33:883-890
E. J. W. van Veen •

W. E. Monteban-Kooistra •

J. H. J. M. Meertens · J. J. M. Ligtenberg ·

J. E. Tulleken · J. G. Zijlstra (®)

University Medical Centre Groningen,

University of Groningen, Intensive and Respiratory Care,

P.O. Box 30.001, 9700 RB Groningen, Netherlands

e-mail: j.g.zijlstra@int.umcg.nl

Tel.: +31-50-3616161

Fax: +31-50-3613216 